\section{AVATARES DE UNA «NACIÓN INDIANA»: LA REPRESENTACIÓN Y EXCLAMACIÓN DE FRAY CALIXTO TÚPAK INKA (1750)}

\author{
ELENA ALTUNA \\ Universidad Nacional de Salta \\ elenaaltuna@gmail.com
}

\begin{abstract}
Elena Altuna
Elena María Altuna es Doctora en Humanidades con orientación en Letras. Investiga en el campo de los estudios coloniales y del siglo XIX; es docente-investigadora de la Universidad Nacional de Salta, Argentina. Autora de El discurso colonialista de los caminantes. Siglos XVII-XVIII, Berkeley: Latinoamericana Editores, 2002 y Retórica del desagravio. Estudios de cultura colonial peruana, Salta: CEPIHA, 2009. Tuvo a su cargo la sección monográfica «Viajes y viajeros coloniales por las américas» de la Revista de Crítica Literaria Latinoamericana, Año XXX, $\mathrm{n}^{\circ}$ 60, Lima-Hanover, 2do. semestre de 2004. Ha participado en numerosos volúmenes colectivos, dictado conferencias y presentado ponencias en congresos nacionales e internacionales y fue Fellow 2007 de la John Carter Brown Library.
\end{abstract}

\section{RESUMEN}

En este trabajo propongo abordar uno de los escritos representativos de la diversidad de ideas y propuestas que caracterizaron al virreinato del Perú en el siglo XVIII: la «Representación y Exclamación rendida» (1750) escrita por el donado franciscano Calixto de San José Túpak Inka, en colaboración con el latinista Antonio Garro, en nombre de la «nación indiana». Aunque perteneciente al género del memorial, varios aspectos lo singularizan y destacan frente al modelo convencional. Dado que nuestro interés se centra en aproximarnos al modo como se gesta discursivamente una «nación» interétnica en un contexto de exacerbado colonialismo, indagaremos en los procedimientos estructurales y retóricos que producen el efecto de una representatividad homogénea. Asimismo, estudiaremos la función que adquiere la estilización de la tradición bíblica (las lamentaciones del profeta Jeremías) para tornar visible una situación de oprobio, que alcanza de esta manera una dimensión transtemporal. Por último, nos referiremos brevemente a otros documentos relacionados con Túpak Inka, que revelan la condición coyuntural de las alianzas interétnicas en el marco de la heterogeneidad sociocultural colonial.

Palabras clave: colonialismo, memoriales, retórica, tradición, etnicidad.

\section{ABSTRACT}

In this paper I intend to approach one of the most representative writings of the diversity of ideas and proposals that characterized the virreinato of Peru in the eighteenth century: «Representación y Exclamación rendida» (1750) written by the Franciscan donatus Calixto de San José Túpak Inka, in collaboration with the latinist Antonio Garro, in the name of the "Indian nation». Although it belongs to the memorial genre, several aspects single out and highlight it in front of the conventional model. Given that our interest is centered in approaching the way that a interethnic nation is discursively gestated in the context of an exacerbated colonialism, we shall inquire in the structural and rhetorical proceedings that produce the effect of an homogeneous representativity. At the same time, we will study the function that the stylization of the biblical tradition acquires (lamentations of the prophet Jeremiah) in order to turn visible a situation of opprobrium, that reaches in this manner a transtemporary dimension. Finally, we shall refer briefly to other documents related to Túpak Inka, that reveal the conjunctural condition of the interethnic alliances in the under the colonial sociocultural heterogeneity.

Keywords: colonialism, memorials, rhetoric, tradition, ethnicity.
Avatares de una "Nación Indiana": la Representación y exclamación de fray Calixto Túpak Inka (1750) 
Para comprender el tipo de " munidad» al que nos referimos será útil incorporar una distinción proveniente de la antropología: "La identidad supone la asunción de una lealtad fundamental y totalizadora tanto desde el punto de vista objetivo como subjetivo; en tanto que la condición se manifiesta como una adscripción coyuntural, que puede eventualmente orientar las conductas y la filiación, pero que tiende a desaparecer junto con la situación que la ha generado» (Bartolomé, 2001, p.5). En buena medida, la «condición» así descrita viene a coincidir con las posiciones del sujeto (simultáneas o sucesivas) de las que habla Rolena Adorno (1988, p.14) para caracterizar las subjetividades atravesadas por la situación colonial.

2

Para Noé Jitrik (1983, p. 21): «Entendemos por 'acción discursiva' un 'querer hacer' de discurso y no meramente un 'querer decir'; restituimos, por lo tanto, al plano del intercambio y de la transformación lo que en el 'decir' estaba sometido a la idea de 'comunicación'. Ahora bien, la posibilidad de tal 'acción' residiría en tres órdenes: 1. Lo 'direccionalidad' (a dónde va el discurso); 2. La 'intención' (qué quiere lograr); 3. La 'instancia de cruce' de funciones sociales en la que inciden los dos primeros y que el discurso conduce y codifica al mismo tiempo».

3

Un ejemplo, por demás conocido, permite corroborar señalado. En el Perú, desde el siglo XVII fue notorio el esfuerzo de los letrados criollos y de las elites indígenas por superar la fractura provocada por la conquista; en este sentido, una táctica de incorporación de los señores étnicos al régimen $\mathrm{Co}$ lonial, tratando de mantener su posición de intermediarios entre éste y los indígenas del común, consistió en la recreación de una noción fundamental de las monarquías europeas: la del poder depositado en un soberano y el carácter inalienable de la "corona». Según Ernst Kantorowicz (1985, pp. 294, 314 passim) esta doctrina -generada en el seno de la teología política cristiana medieval- hacía hincapié en el aspecto corporativo de la "corona» y en la inmortalidad de la dignitas real mediante la atribución de cualidades

Avatares de una "Nación Indiana" la Representación y exclamación de fray Calixto Túpak Inka (1750) ELENA ALTUNA

El siglo XVIII en el virreinato del Perú ofrece un panorama sumamente complejo. De una parte, la llegada de los Borbones al trono español promueve corrientes reformistas ilustradas -básicamente criollas y limeñas-, que propiciarán el conocimiento científico y el análisis de los aspectos susceptibles de mejoras en diversos campos (Rodríguez García, 2006). De otra parte, las políticas tributarias implementadas, la decadencia de la explotación minera, los levantamientos de indígenas y mestizos incidieron profundamente en la agudización de la crisis social que se desarrolla durante este siglo. En efecto, los cambios iniciados con el gobierno del virrey marqués de Castelfuerte (1724-1736) fueron exacerbando las reacciones de quienes se veían más perjudicados, como los sectores indígenas y mestizos (Moreno Cebrián, 1977 y 2000). Scarlett O'Phelan Godoy (1988) señala que, entre 1700 y 1783, se produjeron ciento cuarenta revueltas y rebeliones en distintos puntos del virreinato, como respuesta al creciente malestar.

Tales alteraciones del orden colonial se vieron contemporáneamente acompañadas por la invención de «comunidades», cohesionadas no tanto por factores étnicos como por demandas e intereses comunes. Las alianzas estratégicas no destruyeron, sin embargo, la fuerza de los estereotipos arraigados entre los grupos coloniales, ni tampoco garantizaron la adhesión absoluta de los individuos pertenecientes a un mismo sector ${ }^{1}$. Pero sí constituyeron un ejercicio de posicionamientos dinámicos y coyunturales, que implicaban tanto al presente como al pasado que en cada caso se revisaba y se recreaba.

En este trabajo nos proponemos contemplar la manera en que retóricamente se conjuga la «condición» identitaria de los individuos en pos de la construcción discursiva de una comunidad, dispuesta a presentarse ante el destinatario del mensaje como fuertemente

místicas a la dinastía. En el ámbito peruano, la «metáfora organológica» del cuerpo político y místico que permanece en el tiempo, permitió elaborar representaciones y efigies que vinculaban a los «reyes» incas con los peninsulares, en una línea sucesoria semejante a la planteada por las monarquías europeas. La identificación con esta doctrina supuso desechar buena parte del pasado precolonial, restándole complejidad a los conflictos producidos por ausencia de una ley de sucesión, ignorando el sutil equilibrio de circulación del poder entre las panacas durante el predominio cuzqueño en el ámbito del Tawantinsuyo (Rostworowski, 2006, pp. 153-197), e incluso la posible relación entre la figura del «lnka» y un arquetipo ejemplar (Pease, 1978, pp. $66,72,78)$. Esta relectura del pasado contaba en el si-

cohesionada, en contravención con el espíritu colonial que fincaba su poder en la distancia entre los grupos. Abordaremos el tema en un tipo textual cuyo carácter predominante de «acción discursiva» ${ }^{2}$ posibilitó que anunciaran o acompañaran en la letra las demandas y los levantamientos producidos desde la década de 1720 en el territorio virreinal. Denominados «memoriales», «manifiestos» o «representaciones» estos textos, pertenecientes a una antigua tradición (Quispe Agnoli, 2006), tuvieron particular relevancia en las décadas anteriores a los sucesos de 1780-1781, acaudillados por José Gabriel Condorcanqui (Túpac Amaru II) y Túpac Catari. Destinados al rey, los memoriales le informaban de los abusos sufridos y le solicitaban la implementación de remedios inmediatos. Esa acción comunicativa subraya la existencia de espacios interculturales permeables al ejercicio de prácticas conjuntas, en procura de una efectiva participación en el contexto de una época que aún no se cuestionaba el poder real.

Las modalidades discursivas de los memoriales de agravios se manifestaron en un campo retórico finito. Predomina en los escritos la recurrencia a tradiciones tomadas de varias fuentes, vinculadas entre sí mediante núcleos problemáticos abarcadores. Se generaba de este modo un sistema de representaciones que operaba sobre el eje diacrónico, recuperando fragmentos de memorias culturales. Pero si tenemos en cuenta que se trataba de procesos escriturarios que buscaban la unidad al interior de una comunidad «imaginada», tanto como su legitimación frente a otras comunidades, concluiremos que esta tarea no debió haber sido ligera: supondría lecturas, discusiones alrededor de ellas, intercambio de versiones no siempre coincidentes del pasado, acciones todas estas tendientes a manifestar esa «estructura de sentimiento» de la que habla Raymond Williams (2009, pp. 174-185)³.

glo XVIII con un antecedente famoso: los Comentarios Reales (1609) del Inca Garcilaso de la Vega, obra en que la impronta renacentista de la historiografía permitió a su autor abonar la idea de una paulatina preparación para el advenimiento del cristianismo en las sociedades andinas, al proponer el paso de una edad politeísta y de barbarie a otra edad monoteísta, la civilización incaica. Fue tan convincente la argumentación del Inca, que sus lectores asumieron como propia esa «tradición selectiva», impuesta por sobre otras versiones de pasado. Las representaciones utópicas de una traslación pacífica del poder fueron frecuentes en el periodo colonial sus manifestaciones artísticas se produjeron especialmente en los desfiles y procesiones de la fiesta barroca (Millones, 1995, pp. 51-66) 


\section{Fray Calixto de San José Túpak Inka y sus escritos}

Dos memoriales, pertenecientes a la primera mitad del siglo XVIII han concitado la atención de la crítica. El primero, de 1732, fue escrito por el cacique Vicente Mora Chimo Cápac, procurador y diputado de los indios en la corte española; se titula Manifiesto de los agravios, bexaciones y molestias, que padecen los indios del reyno del Perú. El segundo es conocido por su título abreviado: Representación verdadera, y fue escrito en 1748 . Observa Carlos García-Bedoya:

Este es un texto mucho más complejo, y no sólo en su articulación retórica. Se trata de un texto que no se limita a la denuncia sino que contiene un auténtico y completo programa de reforma política del orden colonial, desde la óptica de las élites andinas, erigidas en portavoces del conjunto de la población indígena o república de indios. En mi opinión, este texto podría tal vez considerarse el más importante de todo el siglo XVIII peruano (García-Bedoya, 2000, p. 222).

Se ha discutido la autoría del texto; un sacerdote franciscano, latinista de sólida formación llamado Antonio Garro, podría haberlo escrito a partir de la información que le proporcionara un compañero. Sin embargo, Francisco Loayza, quien lo edita en 1948, considera que fue escrito por fray Calixto de San José Túpak Inka, y que Garro colaboró con la traducción de las frases en latín (Loayza 1948, p. 3). Es esta opinión la que seguiremos, en atención a otros escritos del fraile que mencionan al texto y a la repercusión que éste tuvo en las circunstancias existenciales que siguieron a su presentación.

¿Quién fue fray Calixto? Sabemos que nació en la sierra peruana, en el pueblo de Tarma, probablemente en 1710. Fue hijo legítimo del español Pedro Montes y de Dominga Estefanía Túpak Inka, descendiente del undécimo soberano Tupak Inka Yupanqui, según la genealogía autenticada que le habría sido remitida a Guatemala por sus parientes en 1744, a través de una autoridad de la Orden. Fray Calixto era reconocido como miembro de la aristocracia andina, su comportamiento cultural era andino, pero su carácter étnico de mestizo no le permitía acceder al sacerdocio. Cuando en 1727 ingresa al convento de los franciscanos, en Lima, lo hace en calidad de «donado", una jerarquía menor destinada a indios nobles y mestizos. De acuerdo con los informes vertidos por sus superiores, participó en las misiones catequizadoras del Cerro de la Sal, adonde fuera enviado por su conocimiento de las lenguas autóctonas. Sus cargos lo llevaron a transitar por diversas regiones del Perú, donde entró en contacto con la dura realidad vivida por indios y mestizos. Probablemente en 1748 redacta el memorial con la colaboración de fray Antonio Garro. La Representación verdadera fue impresa clandestinamente y dada a conocer por su autor a los caciques de Lima con el objetivo de obtener su adhesión. Desde esta ciudad inicia un periplo que, con idénticos fines, le lleva al Cusco. Allí se le unirá otro franciscano, el criollo fray Isidoro de Cala y Ortega, con quien decide viajar a España. Ninguno de los dos contaba con la autorización de los superiores de la Orden para efectuarlo. Este viaje se inicia en setiembre de 1749 y finaliza en agosto de 1750. Pero lo que le otorga un carácter extraordinario es la circunstancia de que, al día siguiente de arribar a Madrid, el 23 de agosto, fray Calixto logra poner en las manos de Fernando VI el memorial, durante un paseo del soberano, sorteando de esta manera las innumerables trabas del protocolo y de los organismos administrativos.

En 1948, Francisco Loayza publicó en la colección «Los Pequeños Grandes Libros de Historia Americana» el tomo Fray Calixto Tupak Inka. El libro contiene una serie de documentos datados entre 1749 y 1760, así como el memorial mencionado. Tomados en

\section{4}

En el Manifiesto de los agravios de Vicente Mora Chimo se denuncian abusos concretos respecto de las tareas urbanas: Con el motivo de aver mucha cantidad de piedra viva en uno de los caminos, que và desde Lima à la Villa de Chancay, intentò Don Francisco de Peña- lillo, Corregidor del Pueblo del Cercado, allanarlo y abrir zanjas, à fin de poner una alameda, desde la Iglesia de Nuestra Señora de Guia, hasta Lima; consiguió su intento, aunque à costa de los infelices Indios, pues les ha hecho trabajar, sin pagarles jornal, darles de comer, ni herramientas, ni tampo- co para la compostura de estas; y si alguna vez le pedian algo, decia, ocurriesen al Virrey à que se lo diese: esto con malos terminos, y algunos rigores, que fuè causa de que aquellos miserables tolerasen con paciencia semejante trabajo" (MS 1732, f. 7). Recordemos que el terremoto de 1746 destruyó

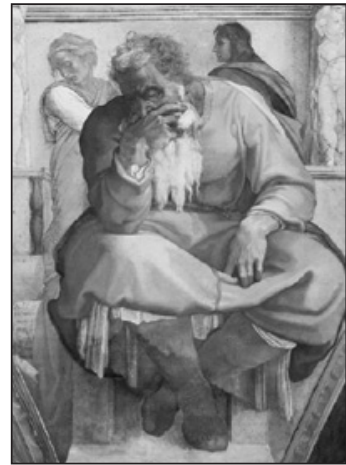

Imagen de Jeremías, por Miguel Ángel. Capilla Sixtina

de la nación judía, cuando este pueblo avanza hacia su ruina; por ello, su mensaje conlleva la marca del peligro y de la tragedia nacional que se avecina por haber quebrantado la alianza con Yavé. Jeremías es el profeta que clama en soledad, el que se opone a los «profetas de corte» dóciles a las decisiones del poder real; será perseguido por sus paisanos de Anatot y excomulgado. Se reconocen dos momentos en la prédica de Jeremías: el primero corresponde al año 605, cuando Nabucodonosor, rey de Babilonia, ocupa la tierra palestina. El segundo ocurre el año 586, cuando este rey pone sitio a Jerusalén y deporta a sus habitantes. En esta instancia el profeta modifica su mensaje, tornándolo esperanzador, al anunciar la futura restauración de Israel en su tierra, como resultado de una nueva alianza espiritual con Yavé. Más allá de las bases históricas que provocaron la migración del pueblo hebreo, se acepta un núcleo fundamental indudable: el éxodo, que representa un estado de esclavitud humillante para un pueblo orgulloso y nacionalista. El hecho del éxodo marca un antes y un después en su historia, pues a partir de ese suceso Israel dejará de ser un conjunto de clanes para convertirse en un pueblo unido. Además, constituye desde una perspectiva simbólica un episodio que ha trascendido sus circunstancias específicas para expresar la esclavitud del pecado y la posterior redención: "el éxodo no es únicamente un suceso ya pasado; para la Biblia es una realidad que cada uno de los creyentes, reactualizando la palabra antigua, puede recrear en su 'hoy'; es una presencia que hace renacer el compromiso y la esperanza» (Rossano, Ravassi, Girlanda, 1990, p. 640).

Tradicionalmente, a Jeremías se le ha asignado un lugar especial en la serie de los profetas, debido a que hubo de enfrentar las situaciones más trágicas
Avatares de una "Nación Indiana": la Representación y exclamación de fray Calixto Túpak Inka (1750) 


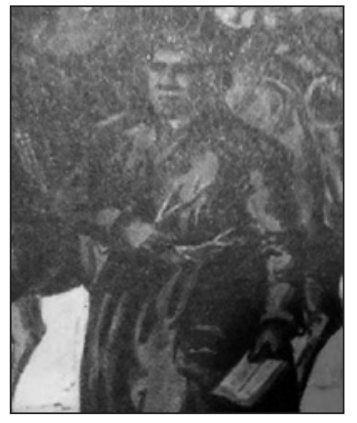

Calixto de San José Túpac Inca. Dibujo de Léonce Angrand
Avatares de una "Nación Indiana": la Representación y exclamación de fray Calixto Túpak Inka (1750) ELENA ALTUNA conjunto los escritos, podemos considerar que constituyen las fases de un proceso de configuración identitaria subjetiva y colectiva. Estas fases surgen de las posiciones que cada quien adopta en su consideración acerca de los «otros» y del «nosotros». El corpus documental constituye, en este sentido, un ejemplo relevante de la conflictividad inherente a la emergencia de una «nación» imaginada, especialmente si se considera la valencia que en este tipo de configuraciones cobra la lejanía entre la metrópolis y las colonias (propicia a la formación de estereotipos) y si la expectativa de obtener algún beneficio se deposita en una legitimidad que sólo puede provenir del centro metropolitano.

\section{El memorial de 1749}

El título completo es Representación verdadera y exclamación rendida y lamentable que toda la nación indiana hace a la majestad del señor rey de las Españas y emperador de las Indias, el señor don Fernando VI, pidiendo los atienda y remedie, sacándolos del afrentoso vituperio y oprobio en que están más de doscientos años - Exclamación de los indios americanos, usando para ella de la misma que bizo el profeta Jeremias a Dios en el capitulo 5 y último de sus lamentaciones (Loayza, 1948, p. 5).

Del extenso título, muy al uso de la época, se desprende una primera consideración referida a la estructura del memorial; en efecto, el mismo busca diferenciar dos esferas: la de la «representación» y la de la «exclamación», aunque en rigor éstas no se presentan en momentos sucesivos, sino entrecruzadas a lo largo de las varias zonas textuales, por lo que la distinción aparente radica en la elección de dos estilos que, abordando las mismas cuestiones, producirán una especie de juego especular expansivo. Esto es, si de una parte se presenta la situación de oprobio que la «nación indiana» experimenta en el Perú y se ofrece al soberano una serie de propuestas concretas para remediarla, de otra, la estilización (Bajtín 1986, p. 258) de las exclamaciones de Jeremías incorporan la denuncia y el «aviso» en una tradición más vasta y antigua que la del pasado prehispánico: la del Antigno Testamento (Estenssoro Fuchs, 1995, p. 47). He aquí una nota que singulariza este memorial frente a otros textos de su género, que acuden a la cita de autoridad o del cedulario indiano para refrendar lo dicho, mas no adoptan un estilo ajeno para sus propios fines, como es el caso de las «Lamentaciones» en el texto de fray Calixto.

Se advierte por esta vía la existencia de una estructura en planos, barroca, productora de un perspectivismo que resulta funcional a la comunidad que se está textualizando, como veremos. Por otra parte, cabe señalar que la demanda concreta de que se permita a los indios viajar a España para presentar personalmente sus quejas ante el rey se ve reforzada retóricamente mediante el encuentro entre dos ámbitos: de un lado, la escritura, que guarda la memoria de lo pasajero; de otro, la representación de la voz, que construye una escena demandante de la voz (de la respuesta) del destinatario. Habría, pues, un notorio paralelismo entre el presente del enunciado y el pasado remoto, en el que se percibe la solitaria voz de Jeremías. Ese paralelismo otorga espesor a la demanda de remedio al oprobio; por lo tanto, genera una tensión que afirma más aún el carácter de "acción comunicativa» que todo memorial de agravios contiene. Veamos ahora los planos que conforman la estructura del texto.

El plano de la «representación» coincide con la estructura de base. En ella se despliegan las dos partes que componen un memorial: la exposición de los agravios y la propuesta de remedios. ¿Qué temas se presentan en este plano? En principio, el texto señala la situación de orfandad en que se encuentra la «nación indiana», excluida del orden sacerdotal e imposibilitada de ocupar cargos y dignidades, en entredicho con la condición de vasallos que les fuera otorgada a sus miembros por cédulas reales. Estas no se concretan en la práctica, pues los españoles transgreden la ley constantemente. Pero no sólo ellos agobian a indios y mestizos; también lo hacen los negros, los mulatos y otras «castas». Así, entonces, a la segregación sufrida en el orden eclesiástico se añade el trabajo esclavizante en los obrajes, las minas y las mitas.

A continuación, se señala que la causa de haber llegado a ese estado de corrupción y violencia radica en la imposibilidad de que sean los propios agraviados quienes denuncien los males ante su rey. La mención al incumplimiento de la real cédula de 1733, en la que Felipe V ordenaba incorporar procuradores indios en las sedes de las audiencias 
y otras ciudades importantes del reino, ejemplifica la ruptura del pacto de obediencia a la voluntad soberana. La siguiente zona textual estará dedicada a canalizar propuestas concretas y a advertir acerca de los males que el presente desgobierno puede desencadenar. En esta instancia, el memorial incorpora los pareceres de autoridades en la materia, por haber sido testigos de vista de lo denunciado: el obispo Bartolomé de Las Casas, el jurista Juan de Solórzano, el padre Juan de Meléndez, el Inca Garcilaso de la Vega. ¿Cuáles son los «remedios» que se proponen al soberano? Hacer que se cumplan las leyes de la Iglesia referidas a los indios cristianos, así como ordenar que se pongan en práctica las cédulas de los reyes católicos para aliviar sus sufrimientos, derogándose por perimidas las dictadas en la época de la conquista; permitir a los indios trasladarse a España para exponer sus quejas; dejar que administren y posean libremente sus bienes, sin intervención de españoles o mulatos; otorgarles el derecho a comerciar sin padecer el aumento de alcabalas, puesto que muchos indios cumplen servicios en las ciudades, formando compañías y ocupándose en diferentes fajinas sin recibir salario por ello ${ }^{4}$; ordenar que se creen colegios y escuelas para instruirlos y admitir la entrada en religión de indios, indias, mestizos y mestizas, así como aprobar su acceso a canonjías y dignidades. Por último, se pide que se creen cargos de protectores fiscales, procuradores y corregidores indios, y se eliminen la mita y el servicio personal.

Como se observa, las propuestas son similares a las de otros memoriales de la época, entre ellos el ya mencionado Manifiesto redactado por Vicente Mora Chimo Cápac (Mathis, 2009). Los asuntos puntuales se remiten a discusiones de antigua data, tales como el derecho de los nacidos en cada reino conquistado a detentar cargos y oficios subalternos, o que la «República de Indios» fuera gobernada por sus propios miembros, independientemente de la «República de Españoles». García-Bedoya (2000, p. 228) señala que el carácter de los remedios es decididamente reformista y así se lo expresa: «se aumentarán el Reino y sus vasallos [...] dándose nuevo modo al Gobierno» (Loayza 1948, p. 45). Las variantes que se advierten radican, a nuestro entender, en la visión dinámica acerca de la ca- ducidad de ciertas leyes y en la incorporación de nuevos actores al conjunto de la «nación», como veremos más adelante.

El segundo plano estructural corresponde a la «exclamación de los indios americanos», cuyo soporte son las lamentaciones del profeta Jeremías. Como señalamos, la incorporación del discurso bíblico obedece a la necesidad de integrar a la «nación indiana» y a la corona en una unidad mayor, que los convierte en miembros del cuerpo místico de la Iglesia. Se trata de una tradición cultural «residual» (Williams, 2009, p. 167) de fuerte impronta en el presente del enunciado. Ahora bien, a qué obedece la elección de la figura de Jeremías. Una razón, de orden histórico, radica en la participación que en el relato bíblico tuvo este profeta; la otra, de sesgo retórico, se apoya en el sentido de las metáforas y el estilo de las lamentaciones, con las cuales el memorial establece un paralelismo ideal $^{5}$. En las «Lamentaciones» se encuentran metáforas espaciales y naturales, interrogaciones constantes, sentencias breves y contundentes, oposiciones violentas y monotonía rítmica. El destierro es la metáfora nuclear del discurso del profeta; alrededor de ella se organiza una semántica de la orfandad, que será retomada por el autor de nuestro memorial para interpelar al destinatario. La representación de la voz se instala desde el inicio del memorial, de idéntica manera a como Jeremías dirige su «oración» a Yavé:

Señor:

Recordare Domine quid acciderit, intuere, et respice oprobium nostrum. (Jeremías, Cap. 5).

¡Oh, Señor! ¡Oh, Monarca Católico! ¡Oh, Emperador de las Indias piadoso, muy católico y muy cristiano! ¡Oh, Señor, acordaos ya de lo que nos ha sucedido en más de dos siglos de oprobios! Atended y ved nuestra afrenta, nuestra herencia (lloraba Jeremías con todo su pueblo). Y nuestro pueblo cristiano indiano, os clama llorando, y os dice su lamento así: (Haereditas nostra versa est ad alienos domus nostra ad estranios). Vuestra herencia, Señor, que como a hijo mayor de la Católica Iglesia, mayor monarca, mayor católico, os cupo en suerte, se ha pasado a los extraños [,] vuestra casa, a los extranjeros. Señor, nosotros los indios en este Nuevo Orbe somos vuestros vasallos; y así somos vuestra herencia, somos vuestra casa... (Loayza, 1948, p. 7).
Avatares de una "Nación Indiana": la Representación y exclamación de fray Calixto Túpak Inka (1750) 
6 Rocío Quispe-Agnoli observa que en el proceso y contexto de producción de la obra de Guamán Poma de Ayala, caracterizada por la perentoria necesidad de mostrar la violenta destrucción del mundo andino, incide "una tradición textual de discursos con gran fuerza persuasiva, entre los cuales se destacan el arte de predicar y el discurso profético de registro apocalíptico" (2006, p. 40). Este señalamiento permite trazar la relación con el memorial, que echa mano a idénticos recursos.

Avatares de una "Nación Indiana" la Representación y exclamación de fray Calixto Túpak Inka (1750)

ELENA ALTUNA
El segmento vocativo inicial presenta el paralelismo que guiará la construcción del texto, generando una fuerte ligazón entre la voz del profeta y su pueblo y la de los indianos y el rey. La palabra sagrada se expone ante el destinatario del mensaje, cancelando cualquier posible «desvío» de la lectura correcta. A partir de esta invocación, los enunciados de Jeremías encauzarán los lamentos de los indianos. En este ámbito se despliega la argumentación que contiene el memorial, en lenguaje metafórico. Así, el destierro expresa la separación entre el padre (el rey) y los hijos (los indios vasallos), instaurado por la apropiación ilegítima de la heredad, en poder de «extranjeros» $\mathrm{y}$ «extraños»: son las sanguijuelas, las raposas. De allí que las iglesias estén como viudas, pues a los hijos legítimos les está vedada la entrada en religión. El destierro acarrea la orfandad, el llanto, la sed de conocimiento y de justicia. Cada tanto, la analogía entre las situaciones de opresión es retomada, como un modo de reforzar el reconocimiento de la tradición: "parece que nos dominan egipcios y no españoles; que nos sujetan $\mathrm{Fa}$ raones y no Reyes Católicos; Nabucos y no reyes españoles cristianos» (Loayza, 1948, p. 10). O bien, en alusión al tema de las indias y mestizas que desean profesar, leemos: «Esto es, Señor, estar las mujeres y vírgenes en Sión y en Judá, humilladas, afrentadas y perdidas» (Loayza, 1948, p. 15). El destierro, entonces, cobra en este nivel de estilización de las lamentaciones de Jeremías, el sentido de la exclusión producida por la imposibilidad de presentarse ante el rey; constituye el tema fundamental en el plano de la «Exclamación», saturada de invocaciones. La mímesis de la voz, que es condición de la presencia, ocupa todo este carril, puntuando el desconcierto, la soledad, el desamparo de quienes se conciben peregrinos habitando el desierto, metáfora esencial para transformar el sonido de la voz en clamor. El rey es el destinatario privilegiado del memorial, único, puesto que son precisamente los mediadores (funcionarios, consejeros) quienes tergiversan la realidad con informaciones falsas: «Pues, Señor, ¿a dónde estáis vos?»; «iSeñor, mirad por vuestra fe y honra y la de Dios...!»; ¡Ay, Señor! Dejadnos desahogar con vos...», son ejemplos de la constante apelación al monarca.

El tercer plano que hemos propuesto para este análisis es el de la alegoría. Su presencia ya fue anunciada por las metáforas elaboradas en el plano anterior, que permiten canalizar dos grandes alegorías, reinscribiendo este memorial en el corpus mayor de la literatura jurídica, cronística y sermonial. Se trata del rey velado (o del rey que duerme), por una parte, y del mundo al revés (o de la inversión del orden), por otra. Tomadas de varios pasajes bíblicos, fueron evocadas por los letrados coloniales desde el siglo XVII, con muy escasas variantes. Semánticamente expresan esa disforia que la situación de lejanía del centro imperial provocaba en los diferentes grupos coloniales, especialmente en los criollos y en las capas indígenas dirigentes. Juan de Solórzano y Guamán Poma de Ayala, tanto como Buenaventura de Salinas y Córdoba acudieron a ellas para denunciar la expoliación de los indios y la falta de armonía entre los distintos miembros del cuerpo de la monarquía ${ }^{6}$.

\section{La construcción de la «nación indiana»}

El análisis de la estructura barroca del memorial facilita el acercamiento al modo en que cada plano contribuye al proyecto total de obtener satisfacción a las demandas de la «nación indiana». Parte de la densidad observada en este texto tiene que ver con el hecho de que, contemporáneamente al desarrollo de los planteos, se realiza el proceso de construcción de la comunidad representada. Esta se diseña como homogénea, puesto que es el resultado de negociaciones culturales conducentes a una alianza entre sectores que comparten una agenda de intereses. A la vez, genera sus propios límites, condición de existencia de toda «comunidad»; por lo tanto produce heterogeneidades, exacerbadas en la situación colonial.

El proceso conjuga dos procedimientos: la escisión y la apropiación de imágenes de la otredad y de la identidad. Así, el memorial representa, según reza su título, a «toda la nación indiana». El colectivo reaparece, pocas líneas más adelante, portando ahora una clara señal para el destinatario: «nuestro pueblo cristiano, indiano». La anteposición de «cristiano» ubica al pueblo como integrante de una monarquía católica universal, cuyos vasallos ostentan tal condición por el hecho de haber sido evangelizados. De este posicionamiento se desprende una primera escisión, en el eje de la temporalidad: quienes ahora claman ya no son idólatras, como sí lo fueron sus antecesores. La reafirmación de la fe acentúa la ficción 
del lazo parental: el rey de España es ahora el padre y, como padre católico, lega a sus hijos legítimos tal condición:

(Patres nostri peccaverunt, et non sunt, et nos iniquitatem eorum portavimus). Nuestros antiguos padres, los Reyes Incas y demás gentiles pecaron en la prolongada y multiplicada idolatría, es verdad; pero ya no son nuestros padres, y ellos y nosotros cargamos hasta ahora sus iniquidades. ¿No sois vos, Señor, nuestro Padre, nuestro Señor y nuestro Rey? (Loayza, 1948, p. 11).

La siguiente escisión se produce en el presente y opera sobre el eje de la espacialidad. Está referida a los «indios bárbaros», secuaces de «un indio o mestizo, no conocido por nosotros». La toma de distancia frente a este grupo es definitiva; responde al objetivo de despejar dudas sobre posibles contactos con los rebeldes liderados por Pablo Chapi o Juan Santos Atahualpa, entre 1742 y 1750, en la zona de la ceja de selva de las provincias de Jauja, Tarma y Huánuco. «Unos pocos indios bárbaros y rústicos, desnudos y sin concierto militar», se dirá más adelante, restándose importancia a una situación conflictiva para el gobierno virreinal, que sumaba fracasos con cada una de las expediciones enviadas para acabar con el movimiento guerrillero. La circunstancia de que éstos se movieran en una región de frontera con los grupos altoamazónicos (los denominados «chunchos») permite la rápida apropiación del estereotipo eurocéntrico del «bárbaro». El desprecio expresado por fray Calixto era compartido por los franciscanos que misionaban en el Cerro de la Sal, cuyos temerosos informes calificaban al líder como «el monstruo más abominable», «este monstruo de errores», «el Chuncho», «el Levantado». Estos datos nos permiten advertir una vez más cómo incide la razón colonial en las construcciones identitarias, exacerbando las diferencias grupales y generando un discurso de exclusiones, que

suele incorporar ideologemas del colonizador. En efecto, tal como lo demuestran los más recientes estudios, la llamada «Revolución de la Montaña» tuvo una expresión muy diferente a la nebulosa en que la envuelve fray Calixto $^{7}$, quien debió haber estado al tanto de la importancia que tuvo en el contexto de la época. Finalmente, en un grado extremo de distanciamiento se ubica a "la nación etiópica, negra, esclava, vil y sierva». El fragmento del memorial que citamos a continuación es mostrativo de la dimensión pasional que había adquirido en el siglo XVIII el sistema de castas:

¿Hay mayor oprobio que el nuestro? ¿Qué una generación extraña, adusta y servil sea de mejor condición que la de los Indios? ¿Qué el negro esclavo se pueda libertar, y quede libre para irse donde quisiere, $y$ pueda pasar a España; y el Indio, aun el noble, sea tributario y mitayo de vuestros siervos, y no tenga albedrío para libremente vivir donde le fuere conveniente, y no tenga modo de pasar a España a ver a su Rey, y mostrarle sus heridas? ¿Qué el mulato y zambo, nacido de los negros, sea libre y no pague tributo; y el indio pagándolo siempre, jamás se liberte de su abatimiento; y mestizo, hijo del español sea envilecido por lo que tiene de indio? (Loayza, 1948, p. 12).

De esta manera se va diseñando una comunidad que, inicialmente nucleada alrededor de los «indios nobles y principales», incorpora a los mestizos y a las mujeres indias y mestizas. La muy rápida mención a lo racial («nuestra pálida piel») propone una visión positiva del mestizaje ${ }^{8}$, a salvo de la «mancha de color» que estigmatizaba a las castas. La presencia de la mujer en el memorial amerita un tratamiento especial, centrado en la remisión al pasado incaico, que ahora es valorado positivamente, tomando como texto fuente los Comentarios Reales del Inca Garcilaso de la Vega, quien refería que en «la gentilidad ciega» existían casas para doncellas escogidas, en las que preservaban su virginidad. Por el contrario, en

llamado «taita Inca», "Santos Atagualpa», se concentraban grupos de indios alto-amazónicos, que no fueron dominados por los incas. De otro lado, las versiones sobre las auténticas motivaciones que llevaron a Juan Santos a producir un movimiento tan extenso en el tiempo y a contar con adeptos de diferente condición, tampoco aportan seguridad. De la lectura de algunos documentos se desprende que pudo haber una transformación en su ideario. Al principio se lo muestra como un ferviente católico, pero más tarde es presentado como un apóstata, en confrontación absoluta con el dogma

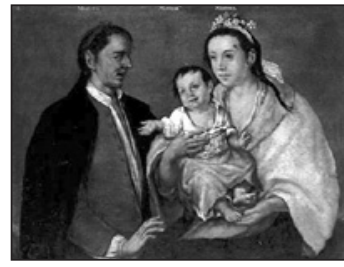

Imagen de castas. Perú, siglo XVIII

católico. Una «relación», fechada en Madrid en julio de 1750, de fray Joseph de San Antonio, Comisario de la Misión de Infieles del Cerro de la Sal, recoge cada una de las "proposiciones heréticas» difundidas por el rebelde. (Microfilm obtenido de la biblioteca americana de José Toribio Medina, de Brown University, con la nomenclatura HA-M193-35).

8

El acercamiento entre indios $y$ mestizos ha sido tradicionalmente rechazado. Pero en los hechos, la coyuntura planteada por el virrey Castelfuerte propició la unidad a partir de los comunes vejámenes sufridos. En efecto, en 1750 varios decretos redujeron el estatus de los mestizos, impidiéndoles ejercer el cargo de notarios o escribanos, así como el ingreso a la Universidad de San Marcos y a las órdenes religiosas. Ese mismo año se descubrió una conspiración de caciques en Lima (22 murieron ahorcados) y estalló una rebelión en la provincia de Huarochirí. A los alzados se les encontró un documento que guarda fuertes similitudes con el memorial de fray Calixto (O'Phelan Godoy, 1988, pp. 111-115). Flores Galindo, a propósito del examen de los censos, observa que el siglo XVIII se caracteriza demográficamente por el incremento de la transculturización y el mestizaje; alrededor del $20 \%$ de la población fue considerada mestiza. Hay otro aspecto que este historiador destaca: la movilidad económica y social, "siendo lo común que una persona [ ] pudiese ser indio por la casta, considerado español en términos culturales $y$, en función de su oficio (arriero o artesano), vinculado a los mestizos; o, como en el caso de los curacas, que siendo indios podían pertenecer a la administración colonial, ser considerados por igual con la nobleza española e incluso gozar de múltiples privilegios económicos» (Flores Galindo, 1991, p. 80).

Avatares de una "Nación Indiana": la Representación y exclamación de fray Calixto Túpak Inka (1750) ELENA ALTUNA realidad una estrategia del pro- $\quad$ (2008, p. 69). Alrededor de la pio líder para evitar su recono- 


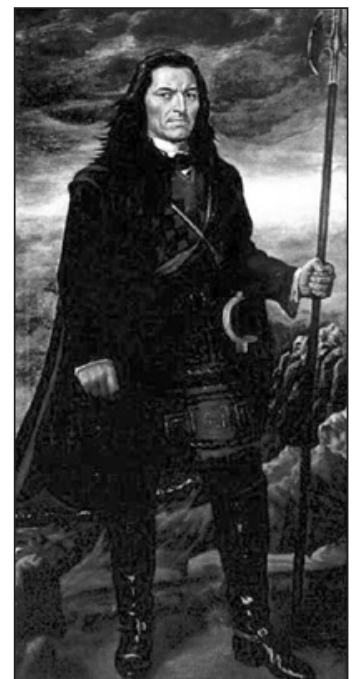

Retrato de Tupac Amaru II. Anónimo, siglo XIX

Avatares de una "Nación Indiana": la Representación y exclamación de fray Calixto Túpak Inka (1750) ELENA ALTUNA doscientos años de monarquía católica no se fundaron conventos para mujeres indias. Este núcleo problemático avanza, asimismo, sobre la humillación que sufrían al ser igualadas con mulatas y negras de servicio, bajo la común denominación de donadas. "¿Qué no reciban, Señor, en los conventos de monjas a las indias y mestizas para religiosas, ni aun legas, si solo para donadas, como reciben a las negras, mulatas y zambas para siervas y criadas de las monjas españolas?» (Loayza, 1948, p. 15). Lo que esta equiparación produjo fue el confinamiento de las indias nobles y mestizas a la condición de siervas, que los señores étnicos contemplaron con dolor, expresándolo en varias oportunidades, como lo demuestran, por ejemplo, los testimonios que Jorge Juan y Antonio de Ulloa recogen en su informe secreto (1748) destinado al marqués de la Ensenada (cfr. Juan y Ulloa, 1991, p. 336). Es, entonces, en el plano de la «representación» donde se ha conformado la comunidad imaginada por el autor del memorial, a la vez que se han denunciado atropellos y ofrecido remedios de diversa índole.

Veamos ahora qué aportan los planos de la «exclamación»y de la «alegorización». El primero propone, como se dijo, una «comunidad» cuyo origen se sitúa en el relato bíblico. Apela, pues, a recrear una memoria colectiva, más allá de las diferencias grupales y temporales. La memoria es un factor esencial en la consolidación de la identidad individual y comunitaria; Maurice Halbwachs había señalado en 1925 que, en rigor, nunca recordamos solos, sino con la ayuda de los recuerdos de otros, insertos en «marcos sociales» portadores de representaciones y de valores. La familia, la religión, los grupos de pertenencia son matrices de los «marcos sociales» históricos. Ellos posibilitan la construcción de un relato que, de acuerdo con Elizabeth Jelin, posee dos notas centrales: «Primero, el pasado cobra sentido en su enlace con el presente en el acto de rememorar/ olvidar. Segundo, esta interrogación sobre el pasado es un proceso subjetivo: es siempre activo y construido socialmente, en diálogo e interacción. El acto de rememorar presupone tener una presencia pasada que se activa en el presente, por un deseo o un sufrimiento, unidos a veces a la intención de comunicarla» (2002, p. 27). Si retornamos al plano de la «exclamación»y tenemos en cuenta lo dicho respecto de las particularidades de la figura de Jeremías, a quien se le atribuye una timidez innata y el esfuerzo por superarla clamando en representación del pueblo desterrado, podemos concluir que la mímesis de voz (e incluso el recurso a la iteratividad que plantea la cita en latín y su traducción al castellano), opera en la búsqueda de «visibilidad» de la «nación indiana», por medio de la analogía con el pueblo hebreo. Con este propósito se actualizan tradiciones y se recrean figuras cuyas particularidades se activan en el presente. En cuanto al plano de la «alegorización», tanto la imagen del rey velado (o dormido), como la de la inversión del orden retoman, en un nivel de mayor abstracción y capacidad connotativa, el tema del «aviso» que el memorial pretende hacer llegar al destinatario. Con notable maestría, el autor del memorial ha ordenando planos y estilos hasta obtener un «todo» caracterizado por la cohesión entre sus partes.

\section{Autorrepresentaciones y representaciones}

Por último, un breve recorrido por el resto de los documentos publicados por Loayza nos permitirá completar el proceso de formación de la «nación indiana», atendiendo a las posiciones que asumen los actores sociales en la instancia de producción y recepción del texto. Una noción capital en el campo de los estudios coloniales es la que refiere a la relación intrínseca entre la forma en que se percibe al «nosotros» y la percepción de los «otros», de modo que la construcción de autoimágenes debe contemplarse en el ámbito de una historia específica de interacciones étnicas, condicionada por las relaciones de poder entre los diferentes grupos.

Fray Calixto Tupak Inka escribe una carta al cabildo de los caciques de Lima, desde Madrid, el 14 de noviembre de 1750. Destina su lectura a los alcaldes de la ciudad, gobernadores y caciques principales, señores nobles de la nación indiana y jefes del batallón de Lima. El objetivo es darles razón de todas las diligencias realizadas por él, desde el momento en que abandona la ciudad y parte hacia Jauja (agosto de 1748) y más tarde al Cusco, llevando el Manifiesto impreso clandestinamente. Este viaje, en busca de apoyo de los señores étnicos, resulta infructuoso en el sentido económico. Fray Calixto no recibe ni una limosna de parte de su gente, por lo 
que decide acudir a los miembros de su congregación. Uno de ellos, fray Isidoro de Cala y Ortega, se le unirá, acompañándolo en la extensa y peligrosa travesía, pues no llevan patentes de los superiores ni tampoco con qué sustentarse, salvo seis pesos que le entregara un cacique. Se dirigen subrepticiamente a Buenos Aires, pasan a Colonia y luego de una travesía de 102 días llegan a Lisboa, en julio de 1750. Fray Calixto lamenta la falta de apoyo, «a mí, que me he expuesto a tantos riesgos y peligros por el bien y libertad de la Nación, ni poderes ni carta alguna me han querido enviar» (Loayza, 1948, p. 55). Hay en esta frase la impronta de una autoimagen que se fortalece ante la soledad, el silencio de los suyos y su resolución de enfrentarse a todos los inconvenientes para entregar el Manifiesto; la analogía con la figura del profeta Jeremías se torna evidente en este pasaje. En el reproche expreso, fray Calixto dice que fueron otros, no los afectados, quienes le brindaron su ayuda, como el criollo fray Isidoro de Cala. Las peripecias narradas sugieren que la «nación», en este momento, adquiere los rasgos de un pacto interétnico que rompe el circuito de los caciques nobles para incorporar a mestizos y criollos andinizados conscientes de la importancia de la causa.

En febrero de 1751 el franciscano dirige una carta suplicatoria al rey, al no haber obtenido respuesta al escrito entregado en sus manos. En ella se presenta como «descendiente del undécimo Rey Inca; llamado Túpac Inga Yupanqui; y por esta alianza tiene cercano parentesco con los más Caciques del Reino del Perú, que descienden de sangre Real» (Loayza, 1948, p. 65). En esta oportunidad opta por ponderar su pertenencia al sector de los indios nobles y caciques, presentando su linaje. Idéntico recorte se produce en la carta que, por esa misma fecha, dirige al presidente del Consejo de Indias. Allí no solamente exalta su calidad de testigo de vista, también advierte los males que pueden sobrevenir de no escuchar la «lamentación de los principales indios». En ambas misivas, entonces, fray Calixto se muestra como el portavoz del grupo dirigente de la «nación indiana», sin mencionar a los mestizos. Los dos certificados que acompañan a esta carta muestran hasta qué punto el acercamiento al poder de la corona, a sus instituciones, exigía una pureza de sangre que ubicase al pretendiente en una de las dos repúblicas.
Fray Isidoro de Cala y Ortega y fray Juan de San Antonio certifican la autenticidad de los papeles de fray Calixto: su "sangre azul», esto es su linaje sin mezcla, su condición de hijo legítimo y sus funciones en el seno de la orden franciscana. Posteriormente, terminados los dos años de noviciado y adquirido el grado de Padre, otras autoridades de la Orden avalarán la solicitud de Fray Calixto de retornar al Perú. Allí se mencionará su conocimiento de las lenguas, en apoyo de su tarea evangelizadora «en aquellas bárbaras tierras». La frase nos reenvía al estereotipo del «bárbaro», fuertemente actualizado en el horizonte del siglo XVIII.

Fray Calixto Túpak Inka salió de España en 1553 con destino a las misiones franciscanas del Urubamba. Poco se sabe de sus actividades en este tiempo, aunque es posible inferir que no olvidara su antigua hazaña y que permaneciera en contacto con los indios del Cercado de Lima, descontentos con la dirección que habían tomado los acontecimientos. Una carta del virrey conde de Superunda al rey, fechada el 15 de enero de 1757, informa acerca del clima insurreccional y del destino del franciscano. La misiva comienza con una referencia a la sublevación de Huarochirí de 1750; luego señala que la impresión del Manifiesto ("que tanto influyó en la conmoción de los indios») se hizo sin licencia y da cuenta de la vigilancia que a mediados de esa década se ejerce sobre el sector indígena. Informa al rey que en 1756 el corregidor comunicó la existencia de movimientos sospechosos alrededor de la celda de un fraile lego, «mestizo de indio»: se trataba de fray Calixto, a quien se le incautaron sus escritos y se lo recluyó, impedido de escribir, hasta tanto se cumpliera la orden de abandonar el Perú. Lo más llamativo de la carta se encuentra en los pasajes que permiten aquilatar la influencia que el memorial ejerció sobre «los indios», así como la perspectiva del sector que el conde de Superunda representa: «De esta diligencia no se adquirió otro conocimiento que afianzar más el concepto de que en los indios, por lo general, se conserva el odio a la Nación Española, y el deseo sin aliento de sacudir su yugo» (Loayza, 1948, p. 89). Esta opinión deja ver que únicamente en apariencia se aceptaban las diferencias entre los caciques y los indios del común. Para la ideología colonial sólo existía un colectivo generalizador: los «indios».

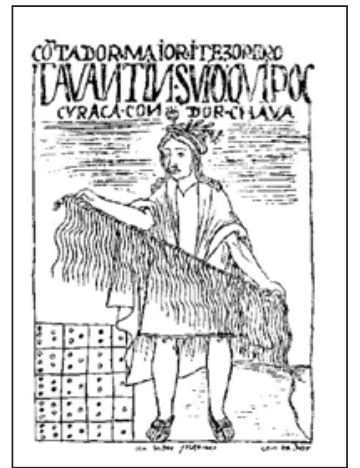

Curaca en Nueva Coronica y buen gobierno, de Guamán Poma de Ayala
Avatares de una "Nación Indiana": la Representación y exclamación de fray Calixto Túpak Inka (1750) ELENA ALTUNA 
La serie de documentos relevados amerita una última reflexión. Contemplada desde la perspectiva de las autoridades coloniales, la difusión del memorial sólo consiguió acrecentar sospechas y prevenciones respecto de la «nación indiana»; en ningún momento se aceptó la existencia de un grupo cohesionado por otras razones que no fueran simplemente las raciales; antes bien, como se lee en la carta del virrey, el término «mestizo de indio» conlleva un sentido peyorativo, que canaliza el desprecio profundo del grupo hegemónico por las «mezclas». Los textos estudiados muestran, primero, el carácter coyuntural de las alianzas interétnicas en pos de la forja de una comunidad «imaginada» y, segundo, una dinámica posicional que oscila entre el acercamiento de indios nobles y mestizos y su distanciamiento, provocado por la negación o la censura que la acción conjunta recibe como respuesta a las demandas de reparación.

En cuanto al destino de fray Calixto de San José Túpak Inka, un documento fechado en diciembre de 1760 en Granada informa de su arribo al Convento de la Recolección de San Francisco del Monte Desierto de Adamuz, así como de la expresa prohibición de abandonarlo. Nada más se sabe de él. La Representación verdadera y Exclamación rendida también terminaría reducida al silencio; pero seguramente sus «avisos» fueron recordados tres décadas después, cuando la rebelión incendió el mundo andino en 1780 .

\section{Bibliografía}

Adorno, Rolena (1988), «Nuevas perspectivas en los estudios literarios coloniales» en Revista de Crítica Literaria Latinoamericana, Año XIV, n ${ }^{\circ} 28$. Lima, 2do. Semestre, pp. 11-27.

Bajtín, Mihaíl (1986), Problemas de la poética de Dostoievski, trad. Tatiana Bubnova. México, FCE.

Bartolomé, Miguel Alberto (2001), «Etnias y Naciones. La construcción civilizatoria en América Latina», Cuadernos de Etnología. Diario de campo, México, CONACULTA - INAH., marzo, pp. 3-18.

Avatares de una "Nación Indiana": la Representación y exclamación de fray Calixto Túpak Inka (1750)

ELENA ALTUNA las ideas y los movimientos sociales en los Andes, siglo XVIII, Cusco, Centro de Estudios Regionales Andinos «Bartolomé de Las Casas», pp. 33-66.

Flores Galindo, Alberto (1991), La ciudad sumergida. Aristocracia y plebe en Lima, 1760-1830, Lima, Horizonte.

García-Bedoya, Carlos (2000), La literatura peruana en el periodo de estabilización colonial, Lima, Universidad Nacional Mayor de San Marcos-Fondo Editorial.

Jelin, Elizabeth (2002), Los trabajos de la memoria, Madrid, Siglo XXI.

Jitrik, Noé (1983), Los dos ejes de la cruz, México, Universidad Autónoma de Puebla.

Juan, Jorge y Antonio de Ulloa (1991), Noticias secretas de América, edición de Luis J. Ramos Gómez, Madrid, Historia 16.

Kantorowicz, Ernst (1985), Los dos cuerpos del rey. Un estudio de teología política medieval, versión española de Susana Aikin Araluce y Rafael Blázquez Godoy, Madrid, Alianza.

Lienhard, Martín (2008), Disidentes, rebeldes, insurgentes. Resistencia indígena y negra en América Latina. Ensayos de historia testimonial, Madrid, Iberoamericana-Vervuert.

Loayza, Francisco A. (1948) Fray Calixto Tupak Inka, Lima, Los Pequeños Grandes Libros de Historia Americana. Tomo XV.

Mathis, Sophie (2009), «Une figure de la première globalisation de l'Amerique espagnole: Vicente Mora Chimo ou l'itinéraire original d'un cacique hispanisé de la côte nord du Pérou à la Cour d'Espagne au début du XVIII ${ }^{\circ}$ siècle» en Nuevo Mundo Mundos Nuevos [en línea], URL: <http://nuevomundo.revues.org/ index55648.html>.

Millones, Luis (1995), «Las ropas del Inca: desfiles y disfraces indígenas coloniales» en Revista de Crítica Literaria Latinoamericana, Año XXI, No 41, Lima-Berkeley, 1 er. Semestre, pp. 51-66.

Mora Chimo, Vicente (1732), Manifiesto de los agravios, bexaciones, y molestias que padecen los indios del Reyno del Peru, MS conservado en la John Carter Brown Library, Brown University, Rhode Island. Moreno Cebrián, Alfredo (1988), Túpac Amaru, el cacique inca que rebeló los Andes, Madrid, Anaya.

Moreno Cebrián, Alfredo (2000), El virreinato del marqués de Castelfuerte. 1724-1736. 
El primer intento borbónico por reformar el Perú, Madrid, Catriel.

Nacar Fuster, Eloino y Alberto Colunga Cueto (1973), Sagrada Biblia, Madrid, BAC.

O’Phelan Godoy, Scarlett (1988), Un siglo de rebeliones anticoloniales. Perú y Bolivia 1700-1783, Cusco, Centro de Estudios Rurales Andinos «Bartolomé de Las Casas».

Pease G. Y., Franklin (1978), Del Tawantinsuyu a la Historia del Perú, Lima, IEP.

Quispe-Agnoli, Rocío (2006), La fe andina en la escritura: Resistencia e identidad en la obra de Guamán Poma de Ayala, Lima, Fondo Editorial UNMSM.
Rodríguez García, Margarita Eva (2006), Criollismo y Patria en la Lima Ilustrada, Buenos Aires, Muiño y Dávila.

Rossano, P., G. Ravasi y A. Girlanda (1990), Nuevo Diccionario de Teología Bíblica, Madrid, San Pablo.

Rostworowski de Diez Canseco, María (2006), Historia del Tabuantinsuyu, Lima, IEP/Promperú.

Williams, Raymond (2009), Marxismo y literatura, trad. Guillermo David, Buenos Aires, Las Cuarenta.

Fecha de recepción: 14/02/2013

Fecha de aceptación: 29/07/2013 